\title{
Power Efficiency Optimization of Switched Reluctance Generator (SRG) Using Power Disturbance Maximum Power Point Tracking (MPPT)
}

\author{
Sibonelo G. Magagula*
}

Mangosuthu University of Technology (Electrical Engineering Department), P.O box 12363 Jacobs, Durban 4026, South Africa.

*Corresponding author. Tel.:+2774 658 4483, +2731 907 7377; email: som.magagula@gmail.com, magagula@mut.ac.za

Manuscript submitted July 15, 2017; accepted August 21, 2017.

doi:10.17706/ijcee.2017.9.2.445-455

\begin{abstract}
Power efficiency optimization of switched reluctance generator (SRG) using power disturbance maximum power point tracking (MPPT) for wind generation system with fixed-step and variable-step is presented in this paper. The operating principle of the power disturbance MPPT control method is to detect the change of output power and change of shaft speed to adjust the phase current of SRG. This is independent of the wind turbine characteristics to track maximum output power of the wind turbine is developed is basically the extended adaptation of the hill climb searching (HCS). The presented MPPT method is modelled and simulated in MATLAB/SIMULINK software to verify and investigate it performance under fixed step and variable step.
\end{abstract}

Key words: Wind power generation system (WPGS), switched reluctance generator (SRG), power disturbance maximum power point tracking (MPPT), generator efficiency.

\section{Introduction}

Recently, due to the large global consumption of power, researchers on renewable energy sources, like photovoltaic, wind power, hydro energy and others are being conducted. Among all renewable energy sources wind power energy presents the higher global growth in the past years, due to the improvement in power electronics and development in wind generator structures, which has made it possible to extract optimum power with high quality through wind power generator. At the moment are many existing generators, usually are induction generators, doubly fed induction generator (DFIG), and permanent magnet induction generators (PMIG) or permanent magnet induction generators. The speed of these induction generators is approximately to a constant value. Therefore the wind generation system utilization factor cannot maintain the optimal value during variation of wind speed.

Switched Reluctance Generators (SRG) offers superior performance under special environment, because of their inherent advantages such as rug, robustness, low cost, and possible operation in high temperature or in harsh environments. This makes the SRG a candidate for such application such as aircraft engine starter/generator, automotive starter/alternator and wind generator system [1]-[3]. Furthermore there are perfectly operate under speed variations, vast range of speed and flexible in control, which makes SRG superior then DFIG and PMIG in wind generation system [4]. 
Maximum power point tracking (MPPT) is one of important techniques in wind energy conversion. Several studies have been done recently on MPPT method's base on SRG [5], [6].

In this study a power disturbance maximum power point tracking method with fixed-step and variable-step is introduced, for a wind power generation system based on switched reluctance generator. The power disturbance MPPT control method is to detect the change of output power and change of shaft speed to adjust the phase current of SRG. This is independent of the wind turbine characteristics to track maximum output power of the wind turbine.

\section{Characteristics of Wind Turbine}

The mechanical power in steady state can be extracted from the wind is shown in Equation (1) [7]. The mechanical power derived from wind is:

$$
P_{\text {wind }}=\frac{1}{2} \rho_{a} A v^{3}
$$

where;

$\rho_{a}$ - is the mass density of air (and is relatively constant $=1.24 \mathrm{~kg} / \mathrm{m} 3$ )

$A$-is the circular cross-sectional area in $\mathrm{m} 2\left(A=\pi R^{2}\right)$

$R$ - Is the radius of the circular cross-sectional area in $m$

$v$ - Is the wind velocity in $\mathrm{m} / \mathrm{s}$

The Aerodynamic Power in the rotor is given by

$$
P_{\text {mech }}=\frac{1}{2} \rho_{a} A v^{3} C_{p}
$$

\section{Power Coefficient:}

$$
C_{p}=\frac{P_{m e c h}}{P_{\text {wind }}}
$$

$\boldsymbol{C}_{\boldsymbol{p}}$ - is the turbine power coefficient, which represents the power conversion efficiency of the wind turbine. Also $\boldsymbol{C}_{\boldsymbol{p}}$ is a nonlinear function of tip speed ratio and turbine pitch angle.

Therefore if the air density, the blade radius and the wind speed are constant the output power of the wind turbine will be a function of the power coefficient of the turbine. When the wind speed varies, there is always a specific rotor speed for which the mechanical power of the wind turbine is maximized.

$$
\begin{gathered}
C_{p}=c_{1}\left(\frac{c_{2}}{\lambda_{i}}-c_{3} \beta-c_{4}\right) e^{\frac{c_{5}}{\lambda_{i}}}+c_{6} \\
\frac{1}{\lambda_{i}}=\frac{1}{\lambda+0.08 \beta}-\frac{0.035}{\beta^{3}+1}
\end{gathered}
$$

where:

$\lambda$ - Tip speed ratio;

$\beta$ - Blade pitch angle.

Tip Speed Ratio: In the wind generation system, the tip speed ratio (TSR) of wind turbine blade to wind velocity, is defined as 


$$
\operatorname{TSR}(\lambda)=\frac{\Omega R}{V_{w}}
$$

where:

$\boldsymbol{R}$ - The length of rotor blade [m];

$\boldsymbol{\Omega}$ - Angular velocity of rotor $[\mathrm{rad} / \mathrm{s}]$

$\mathbf{V}_{\mathbf{w}}$ - wind speed of a rotor $[\mathrm{m} / \mathrm{s}]$

Assuming a not fixed-pitch-angle wind turbine, at a specific wind speed Fig. 1, there is an optimum $\lambda$ at which the power coefficient $\boldsymbol{C}_{\boldsymbol{p}}=0.48$ is achieved for $\beta=0$ degree and for $\lambda=8.1$.Cp-max and $\lambda$ opt are fixed for a given wind turbine design. From equation (1) and (6), at different wind speeds. The value of maximum power point can be calculated using any of MPPT methods like $\boldsymbol{T S R}(\lambda)$ control and power signal feedback (PSF) control. $\boldsymbol{T S R}(\boldsymbol{\lambda})$ Control method of MPPT is used by using the optimum value of $\boldsymbol{C}_{\boldsymbol{p}}$ shown in Fig. 2 to obtain the maximum available power from the wind-turbine.

For each wind speed value is a region in which the rotor speed maximizes the mechanical power generated. Therefore, the wind speed below rated speed operation with variable speed rotor increases efficiency in power generation [8]. The profile of optimizing the efficiency of the power generated for variable speed can be expressed by:

$$
P_{o p t}=P_{o p t} w_{r}^{3}
$$

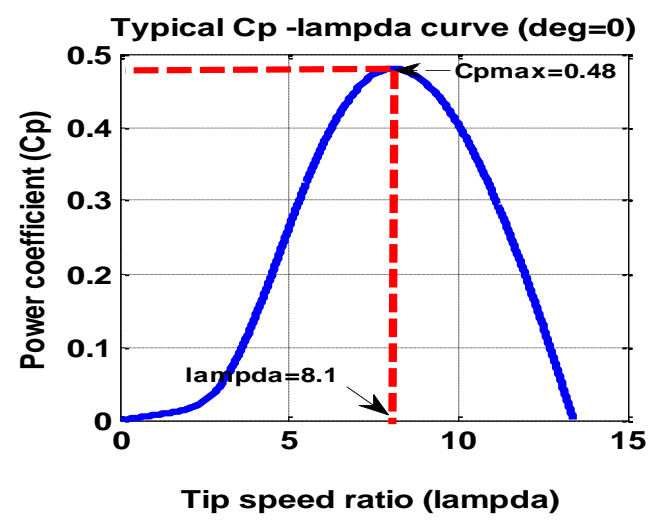

Fig. 1. Coefficient power point.

where $\boldsymbol{P}_{\text {opt }}$ the optimum power and kopt is depends of aerodynamics of the helix, parameters of the wind turbine. For a variable-speed wind turbine with pitch control, optimum power can easily be obtained using appropriate control. However, for small machines that uses a fixed pitch, this mechanisms not possible.

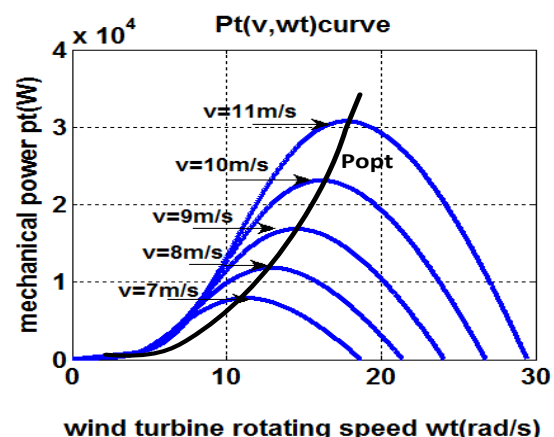

Fig. 2. MPPT control method using TSR( $\lambda$ ). 


\section{Basic Equations of SRG}

The voltage equation for each phase of the SRG is given by

$$
v=R i+\frac{d \emptyset}{d t}
$$

At constant speed, the phase voltage equation is written as

$$
\begin{gathered}
v=R i+L \frac{d i}{d t}+i \frac{d \theta}{d t} \frac{d L}{d \theta} \\
v=R i+\frac{d i}{d t}+e
\end{gathered}
$$

where $\boldsymbol{v}$ the applied voltage is $\boldsymbol{i}$ is the phase current, $\boldsymbol{R}$ is the phase resistance; L is the phase inductance and $\boldsymbol{\theta}$ is the rotor position.

The SRG is singly excited machine excitation energy is supplied in every stroke. The generating energy is turned to the dc-link during the defluxing period. In a soft chopping current controller SRG, the ratio between the electrical excitation and generator power is defined by the excitation penalty [9].

$$
\in=\frac{P_{e x c}}{P_{g}}
$$

where

$$
P_{e x c}=\frac{m}{\theta_{r r p}} \int_{\theta_{o n}}^{\theta_{s}} V_{d c} i_{p h} d \theta
$$

And

The electrical output to load is

$$
P_{o}=\frac{m}{\theta_{r r p}} \int_{\theta_{s}}^{\theta_{q}} u_{p h} i_{p h} d \theta
$$

$$
\boldsymbol{P}_{g}=\boldsymbol{P}_{o}-\boldsymbol{P}_{\text {exc }}
$$

$\boldsymbol{P}_{\boldsymbol{m}}$ Is the mechanical input power, the efficiency in a power generator system is defined by

$$
\eta=\frac{P_{g}}{P_{m}}
$$

The excitation penalty characterizes the reactive power flow and the efficiency is related to power consumption during the generating process, due to mechanical and electrical losses. Therefore excitation penalty reduction increases the phase power factor $(\boldsymbol{P F}=\mathbf{1}-\epsilon)$, whereas efficiency improvements result to loss reduction of the generating system.

\section{Power Disturbance MPPT Strategy}

Power Disturbance MPPT Strategy is independent of the wind turbine characteristics to track maximum output power of the wind turbine is developed is basically the extended adaptation of the hill climb searching (HCS) [10] This MPPT regulates the SRG's phase current to obtain accurate control of the SRG's 
torque and output power. The essential principle is to detect the possible change of output power $\Delta p_{m}(\boldsymbol{k}+$ 1) of generator and change of shaft speed $\Delta \boldsymbol{n}(\boldsymbol{k}+\mathbf{1})$ after an excitation current perturbation $\boldsymbol{\Delta i}(\boldsymbol{k})$ and decide the next current perturbation $\Delta \boldsymbol{i}(\boldsymbol{k}+\mathbf{1})$ according to the variation of $\Delta \boldsymbol{p}_{\boldsymbol{m}}(\boldsymbol{k}+\mathbf{1})$ and $\boldsymbol{\Delta n}(\boldsymbol{k}+$ 1). A smaller $\boldsymbol{i}_{\text {step }}$ decreases the ripplesbut this controller may lose it track ability under fast change of wind condition and equation (15) is to be used to adjust $\boldsymbol{i}_{\text {step }}$ automatically [11].

$$
I_{\min } \leq \Delta i(k+1) \leq I_{\max }
$$

If it results in the increase in power then the same perturbation is applied for the next control instance; otherwise the sign of the perturbation is reversed in order to track in the direction of increasing power as it shown in Fig. 3. Table 1 shows the corresponding change in the next excitation current perturbation. To avoid this unsteady state, the control algorithm uses a "slow increase, fast decrease" technique when adjusting the phase current.

Table 1. The Change and Variable of MPPT Strategy

\begin{tabular}{lcccc}
\hline \hline name & $\boldsymbol{\Delta} \boldsymbol{p}_{\boldsymbol{m}}(\boldsymbol{k}+\mathbf{1})$ & $\boldsymbol{\Delta n}(\boldsymbol{k}+\mathbf{1})$ & $\boldsymbol{\Delta i}(\boldsymbol{k}+\mathbf{1})$ & Change speed \\
\hline \hline Change trend of excitation & $\uparrow$ & $\downarrow$ & $\uparrow$ & Slow \\
\hline \hline Change trend of excitation & $\uparrow$ & $\uparrow$ & $\uparrow$ & Slow \\
\hline \hline Change trend of excitation & $\downarrow$ & $\uparrow$ & $\uparrow$ & Slow \\
\hline \hline Change trend of excitation & $\downarrow$ & $\downarrow$ & $\downarrow$ & Fast \\
\hline
\end{tabular}

A larger current step will be used when the operating point is away from maximum power point and a smaller one when the operating point is in the close vicinity of maximum power point. This MPPT control method is the simplest because it does not require any prior knowledge of the system or any sensor except the measurement of the power in which is subjected to maximization. However these advantages do not make this MPPT control the first choice because in reality it is only feasible in the slow varying system for any WECS.

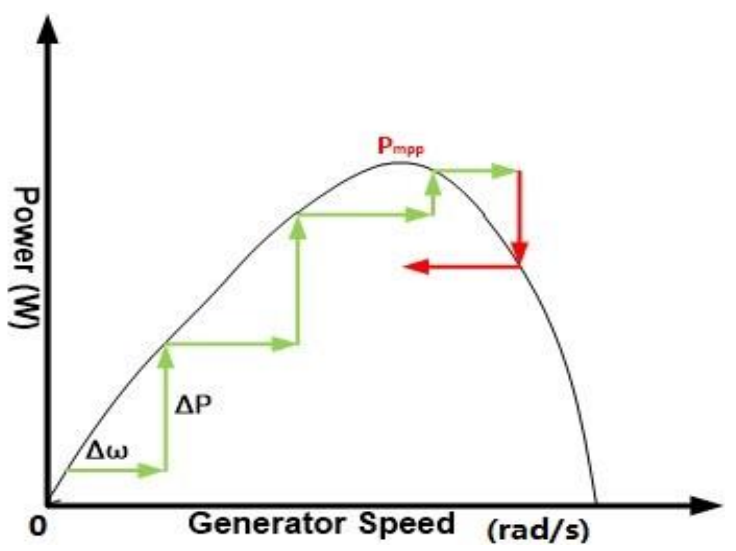

Fig. 3. Principle of MPPT.

\section{Modelling and Simulation of Power Disturbance MPPT Method}

In order to verify the theories of this study, and investigate the performance of the power disturbance MPPT method, simulations are performed in MATLAB SIMULINKTM environment [12]. The Simulink model used in this study, in constructed, using standard elements and blocks form SimPowerSystems ${ }^{\mathrm{TM}}$. Fig. 4 
illustrates the Simulink model which is used in this study. The model consists of a three phase 6/4 pole SRG, which is attached to a fixed pitch, wind turbine with nominal power of $60 \mathrm{KW}$. The SRG is supplied with a $24 \mathrm{~V}$, DC source, and its output is fed into a fixed,50 $\Omega$ resistive load.

The MPPT part in Fig. 4 is used to adjust the SRG's excitation current according to the MPPT algorithm. During the simulation the $m$ is 3 and the step time interval is $0.1 \mathrm{~s}$, the simulation results are shown in Fig. 4 . The starting wind speed is set as $8 \mathrm{~m} / \mathrm{s}$. The wind speed rise to $10 \mathrm{~m} / \mathrm{s}$ after 1.5 seconds, then drops to $9.6 \mathrm{~m} / \mathrm{s}$ after 3 seconds shown in Fig. 5. The wind turbine model and the SRG model are built from the SIMULINK library using equation (2).

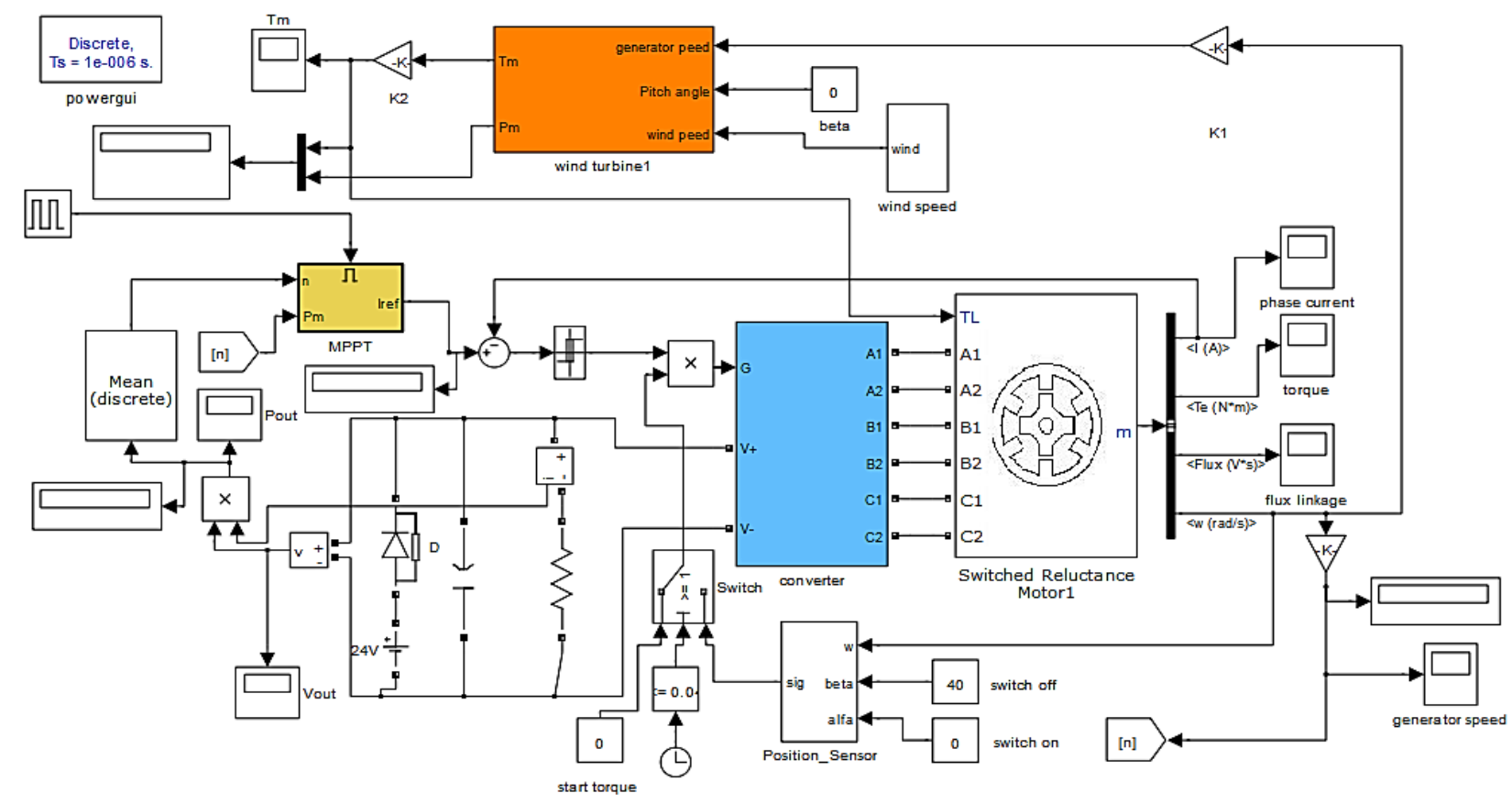

Fig. 4. Model of SRG with MPPT.

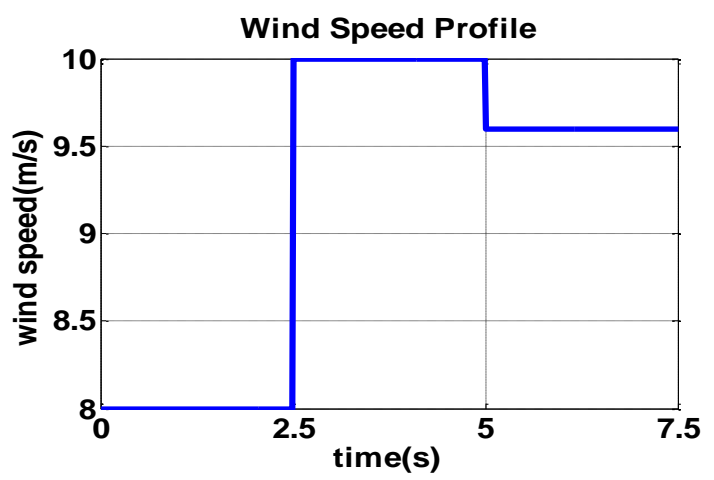

Fig. 5. Wind speed variations.

\subsection{Fixed Step under Variable Wind Speed}

Fixed step size power disturbance always suffers from tracking speed versus control efficiency trade-off. Reference [13] replaces the constant step size by the scaled measure of the slope of power with respect to the perturbed generator speed $\Delta \boldsymbol{P}_{m} / \Delta \boldsymbol{\omega}$ (can also be with respect to the converter's duty ratio). This idea is actually not new as quite a similar one was published in [14] long time back for the HCS in PV systems. The power change is detected by comparing the present and previous power levels, in order to calculate the 
MPPT speed step reference. When the power increases, the speed step is not changed; otherwise, the sign of the speed step is inversed.

\subsection{Variable Step under Variable Wind Speed}

The variable step is expected to adapt a larger step size when the operating point is away from the peak due to the larger magnitude of $\boldsymbol{P}-\boldsymbol{\omega}$ slope and as the peak gets nearer, the step size should automatically approach to zero. But in reality it is only workable for a constant or very slowly changing wind [15]. Then $\Delta \boldsymbol{P}_{m} / \Delta \boldsymbol{\omega}$ will not give a correct measure of the distance from the maximum as the operating point shifts from one power curve to another for different wind velocities. Therefore the algorithm is most likely to result in unnecessary large or small step size during changing wind, resulting into big deviation from the maximum.

\subsection{Simulation Result with Power Disturbance MPPT}

Fig. 6 presents power co-efficient of the wind turbine, as showed that the system reaches maximum point. For fixed-step MPPT control it can track maximum point under any change of wind speed, however it takes longer time to adjust and with disturbance MPPT control is quicker to adjust but when the wind speed decreases it may lose it tracking ability for maximum point. Equation (16) is presented to solve this problem where by $\boldsymbol{i}_{\text {step }}$ is adjusted automatically.

Fig. 7 Chopping current changes with the wind speed when wind speed increases also chopping current increases for both variable and fixed step. Fig. 8 generator speed changes with the wind speed when the wind speed increases also generator speed also increases for both variable and fixed step. Fig. 9 line voltage changes with the wind speed when wind speed increases also line voltage increases for both variable and fixed step. Although the variable step the time to reach maximum power point is faster than fixed step.

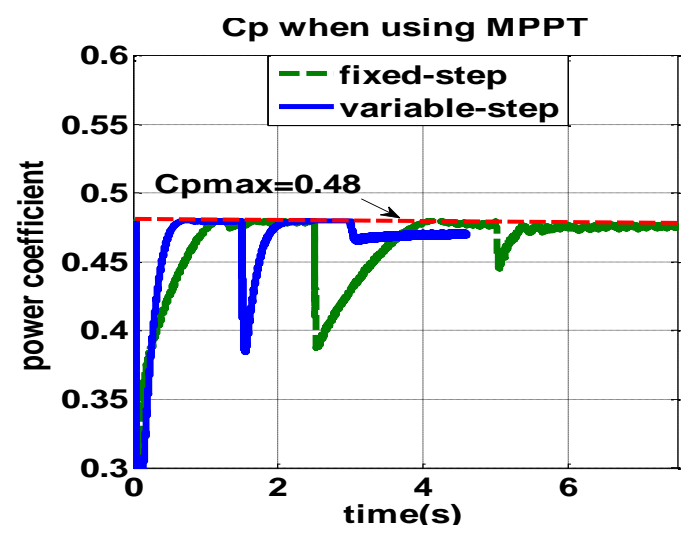

Fig. 6. Power Co-efficient $\mathbf{C}_{\mathbf{p}}$ of variable and fixed step using MPPT.

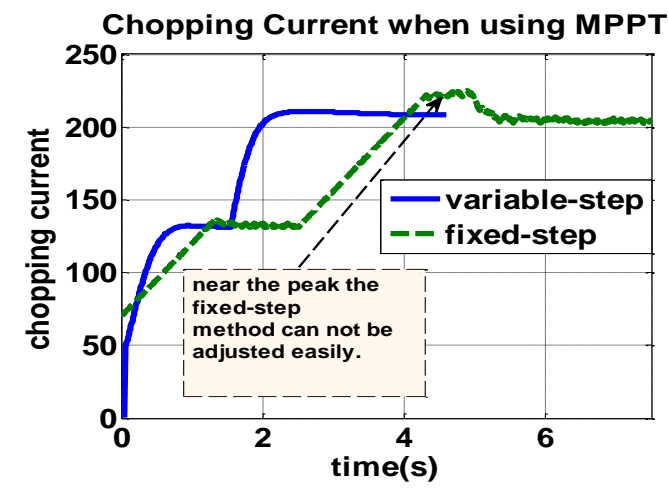

Fig. 7. Current chopping of variable and fixed step using MPPT. 


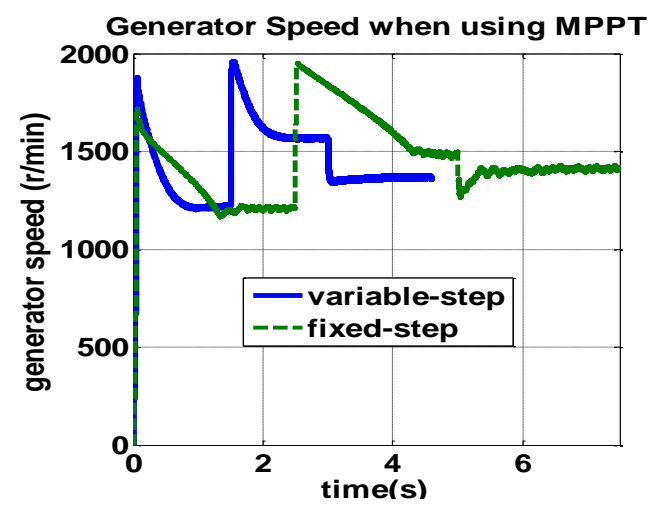

Fig. 8. Generator speed of variable and fixed step using MPPT.

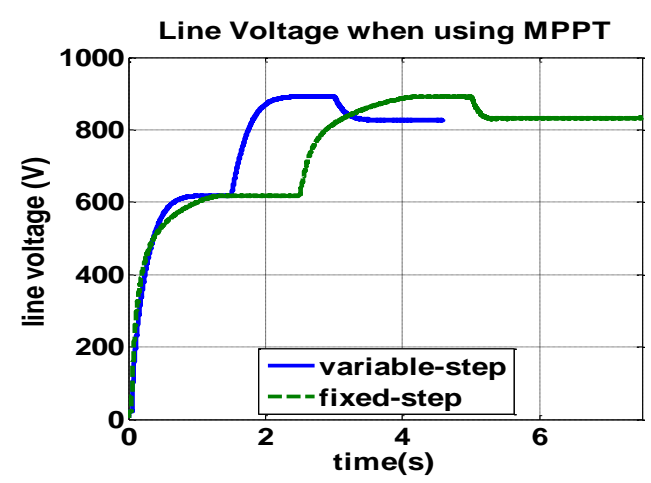

Fig. 9. Line voltage of variable and fixed step using MPPT.

Fig. 10 and Fig. 11 when the mechanical torque of the wind turbine reaches maximum point also magnetic torque reach the maximum point which proves that both methods can reach maximum point tracking.

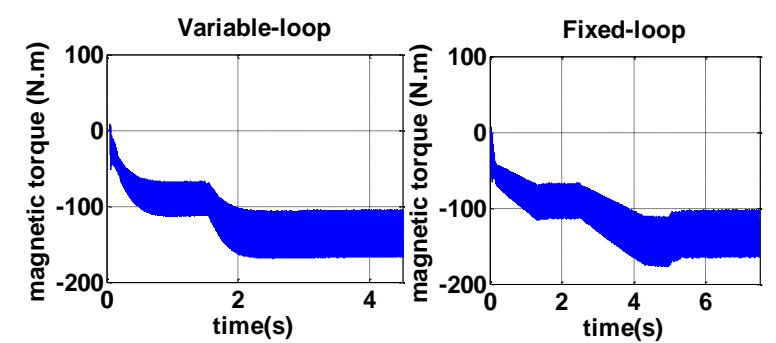

Fig. 10. Magnetic torque of variable and fixed loop using MPPT.

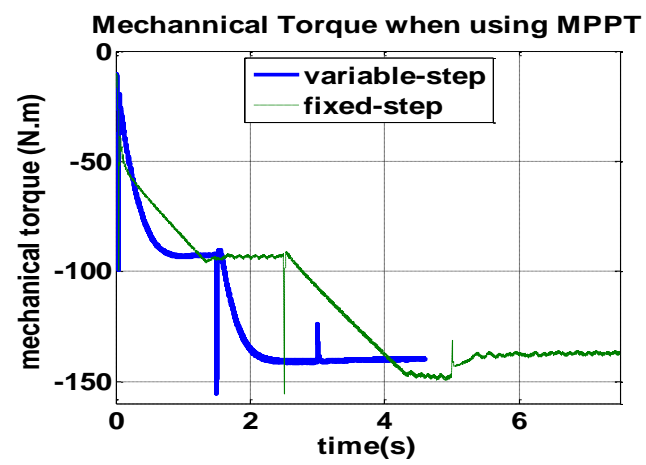

Fig. 11. Mechanical torque of variable and fixed step using MPPT. 
Fig. 12 output power of the generator changes with the wind speed when wind speed increases also chopping current increases for both variable and fixed step. Although the variable step the time to reach maximum power point is faster than fixed step. The generator power efficiency is approximately equal to 69\%. The maximum power point on the Fig. 12 above calculated using equation (15) as shown in the follow Table 2. Which: $\eta$ generation efficiency; $\boldsymbol{P}_{\boldsymbol{m}}$ input mechanical power; $\boldsymbol{P}_{\boldsymbol{g}}$ output power of the generator. However has been discussed in chapter three the effect of the load and chopping current to output power efficiency.

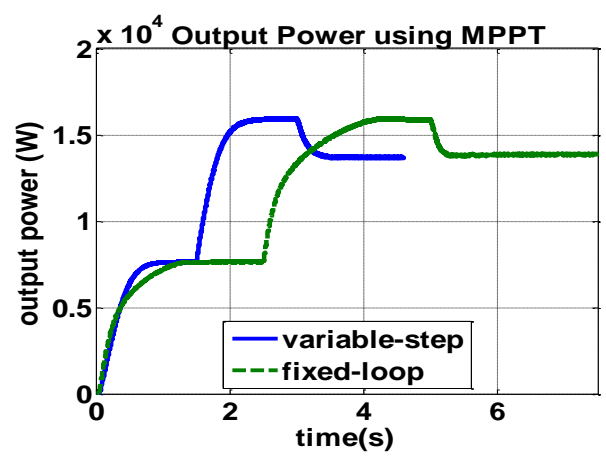

Fig. 12. Output power of variable and fixed step using MPPT.

The load is constant while chopping varies with the change of wind speed; therefore we get different output efficiency as shown in Table 2 and also observed that the high the wind speed is higher efficiency, therefore this system is more suitable for medium and high speed for better maximization of efficiency.

Table 2. Output Power Efficiency Calculation

\begin{tabular}{ccccc}
\hline \hline $\begin{array}{c}\text { Wind Speed } \\
(\mathrm{m} / \mathrm{s})\end{array}$ & $\begin{array}{c}\boldsymbol{I}_{\text {chop }} \\
(\mathrm{A})\end{array}$ & $\begin{array}{c}\text { Calculate Value } \\
\boldsymbol{P}_{\boldsymbol{m}}(\mathrm{W})\end{array}$ & $\begin{array}{c}\text { Simulate Value } \\
\boldsymbol{P}_{\boldsymbol{g}}(\mathrm{W})\end{array}$ & $\mathbf{\eta} \%$ \\
\hline \hline 8 & 131.25 & $1.1822 \mathrm{e} 4$ & $0.765 \mathrm{e} 4$ & $65 \%$ \\
\hline \hline 10 & 210.65 & $2.3091 \mathrm{e} 4$ & $1.5916 \mathrm{e} 4$ & $70 \%$ \\
\hline \hline 9.6 & 208.63 & $2.0429 \mathrm{e} 4$ & $1.3701 \mathrm{e} 4$ & $67 \%$ \\
\hline
\end{tabular}

\section{Conclusion}

In this study, a power disturbance maximum power point tracking (MPPT) method with fixed-step and variable-step is presented, for a SRG wind power generation system. This method is based on monitoring output power of the generator and monitoring shaft speed after an excitation current perturbation and decides the next current perturbation according to the variation, in order to extract the maximum possible wind energy. The results, support the validity of the proposed method, and indicate that the introduced MPPT method, can optimally track the maximum power points in different wind speeds. This simulation is performed under two conditions variable-step and fixed-step and compared the two conditions which one gives better efficiency of the system. As it mentioned above that in both conditions power coefficient maximum point is reached and observed that fixed-step MPPT control can track maximum point in any wind speed of the system but it takes long time to adjust. Obviously, between the two MPPT control methods, simulation time of variable-step method is shorter than that of fixed-step method.

\section{Acknowledgment}

I would like to acknowledge Mangosuthu University of Technology (MUT) for the funding support on my 
first paper publication. Their support made a huge difference in my career.

The author is sincerely thankful to the unanimous reviewers for their critical comments and suggestions to improve the quality of the manuscript.

\section{References}

[1] Viajante, G. P., Andrade, D. A., Gomes, L. C., Freitas, M. A. A., Bernardeli, V. R., \& Silveira, A. W. F. V. (2013). A voltage control strategy for switched reluctance generator. Proceedings of Electrical Machines \& Drives Conference (IEMDC) (pp. 421-426).

[2] Gao, Y. (2012). A review of high power density switched reluctance machines suitable for automotive applications. Proceedings of International Conference on Electrical Machines (ICEM) (pp. 2610-2614).

[3] Eddine, M. J., Imed, M., Mourad, F., \& Habib, R. (2013). Modeling and control of a switched reluctance machine for wind generation. Proceedings of International Conference on Electrical Engineering and Software Application (ICEESA) (pp. 1-5).

[4] Zhang, Q. X., Wang, X. H., Zhu, X. Z., \& Liu, D. J. (2001). A small single-phase switched reluctance generator for wind power generation. Proceedings of the Fifth International Conference on Electrical Machines and Systems (pp. 1003-1006).

[5] Mohseni, M., Niassati, N., Tajik, S., \& Afjei, E. (2012). A novel method of maximum power point tracking for a SRG based wind power generation system using AI. Proceedings of Power Electronics and Drivers System Technology Conference (pp. 330-335).

[6] Yamaguchi, T., Yamamura, N., \& Ishida, M. (2011). Study for small size wind power generating system using Switched Reluctance Generator. Proceedings of IECON 37th Annual Conference (pp. 967-972).

[7] Koutroulis, E., \& Kalaitzakis, K. (2006). Design of a maximum power tracking system for wind-energy-conversion applications. Proceedings of IEEE Transactions on Industrial Electronics (pp. 486-494).

[8] He, Y., Hu, J., \& Rend, Z. (2008). Modelling and control of wind-turbine used under network fault condition. Proceedings of the Eighth International Conf. on Electrical Machines and Systems (pp. 096-991).

[9] Materu, P. N., \& Krishnan, R. (1992). Estimation of switched reluctance motor losses. IEEE Trans. Ind. Appl, 28(3), 668-679.

[10] Nouali, S., \& Ouali, A. (2011). Multi-Layer neural network for sensorless MPPT control for wind energy conversion system using doubly fed twin stator induction generator. Proceedings of 2011 8th International Multi-Conference on Systems, Signals and Devices (pp. I-7).

[11] Xiong, L. X., Xu, B. Y., Gao, H. L., \& Xu, L. (2009). A novel algorithm of switched reluctance generator for maximum power point tracking in wind turbine application. Proceedings of International Conference on Sustainable Power Generation and Supply (pp. 1-5).

[12] SimPowerSystems: Model and Simulate Electrical Power Systems. User's Guide, the MathWorks Inc.

[13] Neammanee, B., Sirisumranukul, S., \& Chatratana, S. (2006). Control performance analysis of feed forward and maximum peak power tracking for small-and medium-sized fixed pitch wind turbines. Proceedings of ICARCV 2006.

[14] RazaKazm, S. M., Goto, H., Hai, G., \& Ichinokura, O. (2010). Review and critical analysis of the research papers published till date on maximum power point tracking in wind energy conversion system. Proceedings of Energy Conversion Congress and Exposition (pp. 4075-4082).

[15] Agarwal, V., Aggarwal, R. K., Patidar, P., \& Patki, C. (2010). A novel scheme for rapid tracking of maximum power point in wind energy generation systems. IEEE Transactions on Energy Conversion, 25(1), 228-236. 


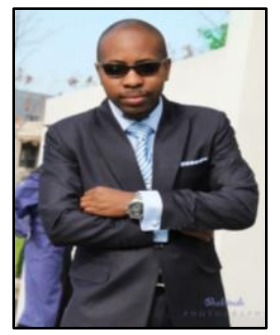

Sibonelo G. Magagula was born in Kwa-Zulu Natal, Durban, South Africa, in 1985. He received the diploma in electrical engineering from Mangosuthu University of Technology (MUT), Kwa-Zulu Natal (Durban), South Africa, in 2010. Got his B.Tech in electrical (Power) engineering from Durban University of Technology (DUT), Kwa-Zulu Natal (Durban), South Africa while he was working for (MUT) as electrical lab technician in 2011. He's also a graduate of Northwestern Polytechnical University (China, Xian) in Electrical Engineering (School of Automation) a master's degree in electrical engineering (Automation) in 2014.

In 2014, he joined the Department of Electrical Engineering, Mangosuthu University of Technology (MUT), as a contract lecturer for 6 months, and after he joined MANI Industries a consulting firm as a junior engineer for a period of two (2) years. In the beginning of 2017 he join again (MUT) in the Department of Electrical Engineering for a fulltime lecturer position. His current research interests include power electronics, electrical machines and drives, power quality, renewable energy, robotics control and electric vehicles (EV)/ hybrid electric vehicles (HEV). Mr. Magagula is a member of South African Institute of Electrical Engineering (SAIEE) from 2015. 